\title{
Erratum to: Computational dialectic and rhetorical invention
}

\author{
Douglas Walton
}

Published online: 11 June 2010

(c) Springer-Verlag London Limited 2010

Erratum to: AI \& Soc

DOI 10.1007/s00146-010-0279-1

Owing to an oversight, the wrong version of the "Abstract" was published. Please find the correct version of the abstract below.

\begin{abstract}
This paper has three dimensions, historical, theoretical and social. The historical dimension is to show how the Ciceronian system of dialectical argumentation served as a precursor to recent computational models like the Carneades argumentation model. The theoretical dimension is to show concretely how these models reveal the interdependency of rhetoric and logic, and so the interdependency of the normative with the empirical. The paper brings this out by identifying points of disagreement in a dialectical format through using argumentation schemes with matching critical questions. The social dimension is to show how the Ciceronian dialectical viewpoint integrates with the use of these computational tools to support the principle of reason-based deliberation that is fundamental to deliberative democracy.
\end{abstract}

The online version of the original article can be found under doi:10.1007/s00146-010-0279-1.

D. Walton $(\bowtie)$

Centre for Research in Reasoning,

Argumentation and Rhetoric (CRRAR),

University of Windsor,

2500 University Ave. W., Windsor,

ON N9B 3Y1, USA

e-mail: dwalton@uwindsor.ca

URL: http://www.dougwalton.ca 